\title{
High-Temperature Behavior of High-Pressure Diecast Alloys Based on the Al-Si-Cu System: The Role Played by Chemical Composition
}

\author{
Elisabetta Gariboldi ${ }^{1}{ }^{*}$, Jannis Nicolas Lemke ${ }^{1}$, Ludovica Rovatti ${ }^{1}$, Oksana Baer ${ }^{2}$, \\ Giulio Timelli $^{3}$ (iD) and Franco Bonollo ${ }^{3}$ \\ 1 Dipartimento di Meccanica, Politecnico di Milano Via La Masa 1, 20156 Milano, Italy; \\ jannisnicolas.lemke@polimi.it (J.N.L.); ludovica.rovatti@polimi.it (L.R.) \\ 2 Laboratory for Machine Tools and Production Engineering (WZL), RWTH Aachen University, \\ 52074 Aachen, Germany; O.Baer@wzl.rwth-aachen.de \\ 3 Dipartimento di Tecnica di Gestione di Sistemi Industriali, Università di Padova, Stradella S. Nicola, \\ 3-36100 Vicenza, Italy; timelli@gest.unipd.it (G.T.); bonollo@gest.unipd.it (F.B.) \\ * Correspondence: elisabetta.gariboldi@polimi.it; Tel.: +39-02-2399-8224
}

Received: 1 April 2018; Accepted: 9 May 2018; Published: 11 May 2018

\begin{abstract}
Al-Si-Cu foundry alloys are widely applied in the form of high-pressure diecast components. They feature hypo- or nearly eutectic compositions, such as AlSi9Cu3(Fe), AlSi11Cu2(Fe), and AlSi12Cu1(Fe) alloys, which are used in the present study. Diecast specimens, with a thickness of $3 \mathrm{~mm}$, were used for tension tests. The short-term mechanical behavior was characterized at temperatures from 25 up to $450{ }^{\circ} \mathrm{C}$. At temperatures above $200{ }^{\circ} \mathrm{C}$, the tensile strength properties (YS and UTS) of the investigated alloys were severely affected by temperature, and less by chemical differences. Material hardness and ductility indexes better highlighted the differences in the mechanical behavior of these age-hardenable alloys and allowed us to relate them to the microstructure and its changes that took place at test temperatures. Thermodynamic calculations were found to be useful tools to predict phases formed during solidification, as well as those related to precipitation strengthening. By means of the performed comprehensive material characterization, deeper knowledge of the microstructural changes of Al-Si-Cu foundry alloys during short-term mechanical behavior was obtained. The gained knowledge can be used as input data for constitutive modeling of the investigated alloys.
\end{abstract}

Keywords: high temperature; tensile properties; microstructural changes; AlSi9Cu3(Fe); AlSi11Cu2(Fe); AlSi12Cu1(Fe)

\section{Introduction}

Al alloys based on the Al-Si-Cu system, specifically of hypo- or nearly eutectic composition, are widely applied to manufacture parts by high-pressure die casting processes (HPDC). They are frequently employed for the production of automotive components where a high strength-to-weight ratio is of great appeal. Even if their chemical composition allows an age-hardening response, and thus the mechanical properties can be improved by suitable heat treatment [1-4], Al-Si-Cu-based alloys are mostly applied in the as-diecast condition.

The high-temperature mechanical behavior of Al-Si-based casting alloys has mainly been investigated for piston alloys [5,6], of nearly eutectic or hypereutectic composition. Only recently has attention been focused on hypoeutectic alloys [7,8]. As a matter of fact, during their lifecycle, structural parts made of these alloys are held at moderate or high temperatures (for example in parts close to heat sources where the high thermal conductivity of Al alloys is appreciated) and the knowledge 
of high-temperature tensile properties in their actual temper condition is of interest. While many experimental studies have been devoted to the thermal stability of Al-Si-Cu casting alloys and to their direct effects on hardness and room-temperature mechanical properties [7,8], less attention has been paid to the temperature dependence of stress-strain curves and the tensile properties in a wide temperature range [8]. Small efforts have also been dedicated to describe the effects of microstructural stability on the mechanical properties after long-term exposure to elevated temperatures, for instance by means of long-term experimental creep tests [9] or tensile testing in a wide range of strain rates [8].

Further, to the authors' knowledge, no direct comparison of the high-temperature behavior of different Al-Si-Cu casting alloys is currently available in the literature, as a function of chemical composition and corresponding microstructural features. As a matter of fact, the mechanical response of Al-Si casting alloys is highly process- and geometry-dependent since foundry defects, as well as process-related microstructural features, can significantly affect properties such as yield strength and ductility [1,2].

The present paper aimed to evaluate the short-term high-temperature behavior of three widely diffused Al-Si-Cu alloys for high-pressure diecasting, which are often proposed as alternative alloys for moderate/high-temperature service. They were then analyzed taking into account the effects of chemical composition and of the correlated microstructural features. For this reason, experimental tests were performed on specimens produced by an optimized and strictly controlled high-pressure die casting process, leading to sound parts (with a very limited amount of pores) with proper microstructure.

\section{Materials and Methods}

\subsection{Alloys and Specimen Manufacturing}

Three secondary $\mathrm{AlSiCu}(\mathrm{Fe})$ alloys were selected within the standard production of an industrial foundry, according to EN 1706 standard [10], in order to investigate a set of widely diffused alloys with different amounts of $\mathrm{Si}$ and $\mathrm{Cu}$, considered as the main elements that can vary the amount of eutectic and secondary precipitates. The selected alloys were EN AC 46000-AlSi9Cu3(Fe), EN AC 46100-AlSi11Cu2(Fe), and EN AC 47100-AlSi12Cu1(Fe), whose actual chemical compositions as well as compositional limits are given in Table 1. The chemistries of the alloys are similar to that of the A380.0 (UNS A13800), A383.0 (UNS A03830), and A413.0 (UNS A04130) alloys, respectively [11]. For the sake of simplicity, the three materials will be hereafter referred as alloys A, B, and C, as shown in Table 1 .

The specimens for the tensile tests were high-pressure diecast using a cold chamber die casting machine. Specifically, the alloys were molten in a 300-kg furnace and held at $690{ }^{\circ} \mathrm{C}$ for $30 \mathrm{~min}$ prior to being diecast. The cavity was specifically designed to produce testing specimens and simple shapes for experimental purposes, with a cast part mass of about $0.9 \mathrm{~kg}$. Both the die design and the process parameters aimed to minimize the porosity level and to obtain a controlled microstructure. Oil circulation channels in the die were used to stabilize the temperature $\left(\right.$ at $\left.\sim 230^{\circ} \mathrm{C}\right)$. The main process parameters were: in-gate speed of about $45 \mathrm{~m} / \mathrm{s}$, filling time of about $10 \mathrm{~ms}$, and intensification pressure at $40 \mathrm{MPa}$. Additional details of the casting procedure, die design, microstructural features, defect content [12-14], and mechanical properties at room temperature [13] have already been described and discussed in previous works and in CEN T/R 16748 [15]. 
Table 1. Experimental chemical compositions (mass \%) of the investigated materials and compositional limits according to EN 1706 standard [10].

\begin{tabular}{|c|c|c|c|c|c|c|c|c|c|c|c|c|c|c|}
\hline & Alloy & & Si & $\mathrm{Fe}$ & $\mathrm{Cu}$ & Mn & $\mathrm{Mg}$ & $\mathrm{Cr}$ & $\mathrm{Ni}$ & $\mathrm{Zn}$ & $\mathrm{Pb}$ & Sn & $\mathrm{Ti}$ & Al \\
\hline \multirow{2}{*}{ A } & EN AC & actual & 8.227 & 0.799 & 2.825 & 0.261 & 0.252 & 0.083 & 0.081 & 0.895 & 0.083 & 0.026 & 0.041 & bal \\
\hline & 46000-AlSi9Cu3Fe & limits & $8.0-11.0$ & $<1.3$ & $2.0-4.0$ & $<0.55$ & $0.05-0.55$ & $<0.15$ & $<0.55$ & $<1.20$ & $<0.35$ & 0.15 & $<0.25$ & $\mathrm{ba}$ \\
\hline \multirow{2}{*}{ B } & EN AC & actual & 10.895 & 0.889 & 1.746 & 0.219 & 0.224 & 0.082 & 0.084 & 1.274 & 0.089 & 0.029 & 0.047 & $\mathrm{ba}$ \\
\hline & 46100-AlSi11Cu2(Fe) & limits & $10.0-12.0$ & $<1.1$ & $1.5-2.5$ & $<0.55$ & $<0.30$ & $<0.15$ & $<0.45$ & $<1.70$ & $<0.25$ & 0.15 & $<0.25$ & $\mathrm{ba}$ \\
\hline \multirow{2}{*}{$\mathrm{C}$} & EN AC & actual & 10.510 & 0.721 & 0.941 & 0.232 & 0.242 & 0.045 & 0.080 & 0.354 & 0.055 & 0.025 & 0.038 & $\mathrm{ba}$ \\
\hline & 47100-AlSi12Cu1(Fe) & limits & $10.5-13.5$ & $<1.3$ & $0.7-1.2$ & $<0.55$ & $<0.35$ & $<0.10$ & $<0.30$ & $<0.55$ & $<0.20$ & 0.10 & $<0.20$ & bal \\
\hline
\end{tabular}


Specimens used for tensile tests are shown in Figure 1. They were flat bars with nominal thickness of $3 \mathrm{~mm}$. The length and width of the gauge length were 35 and $10 \mathrm{~mm}$, respectively. Outside the gauge length, within a distance of $12.5 \mathrm{~mm}$, the width of the specimen gradually increased to the $20 \mathrm{~mm}$ of the gripping ends. Two holes, $6 \mathrm{~mm}$ in diameter, spaced $70 \mathrm{~mm}$ apart, were drilled to insert steel pins fixing the specimens in the loading train. No other machining operation was performed on the specimens. A representative macrograph of a transverse section of a specimen gauge length evidences the low defect amount of the cast parts (see Figure 2) as well as the extension of the skin layer compared to the overall specimen cross-section. The tensile behavior to be derived from these specimens is thus reasonably closer to that of the chill layer than that of the inner regions characterized by a coarser microstructure. Specimens were tested in T1 condition, after a stabilization period following the casting process.

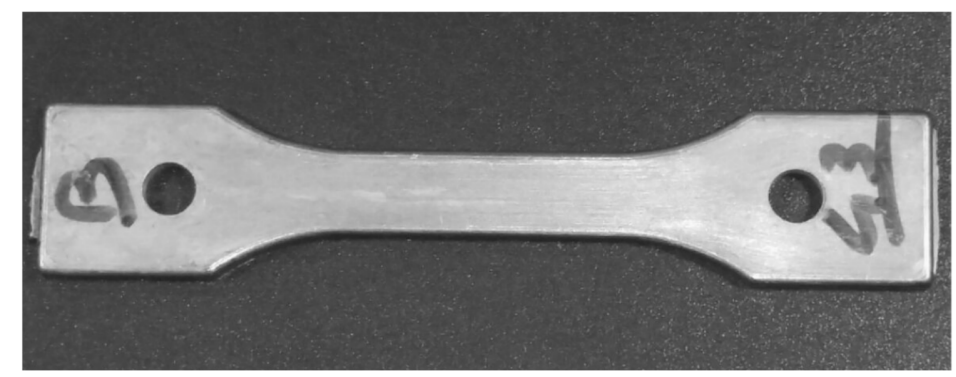

Figure 1. View of a specimen used for the experimental tensile tests.

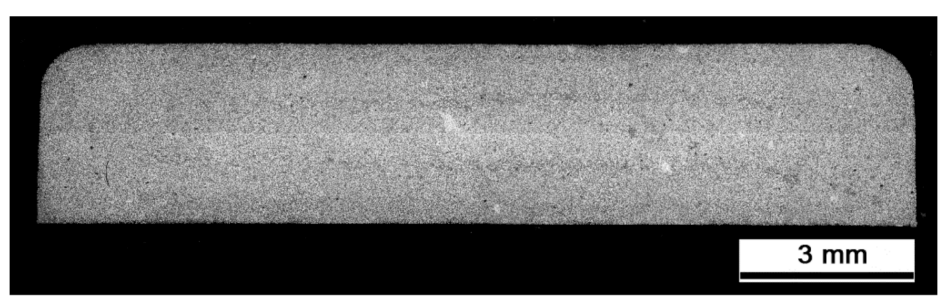

Figure 2. Transversal section of a specimen (alloy A) after metallographic polishing and etching to reveal casting defects and metallurgical features.

\subsection{Tensile Testing}

Tensile testing was carried out in an electromechanical CSR-30 machine (CERMAC, Pozzo d'Adda, 20060 Pozzo d'Adda, Italy), specifically designed for high-temperature testing, equipped with a three-zone vertical furnace, at temperatures in the range of $25-450{ }^{\circ} \mathrm{C}$ with $50{ }^{\circ} \mathrm{C}$ temperature steps. The temperature range extended from the conventional application of the alloys, including moderate- and high-temperature service, to the maximum investigated temperature, $450{ }^{\circ} \mathrm{C}$, which is not far from the temperatures of the solution treatment to which these alloys could be subjected and at which strain could arise from stresses induced by the same component weight, from thermal gradients and, locally, by the presence of pressurized pores [15]. Tests were performed according to CEN ISO 6892-2 standard [16]. The test temperature was measured by three S-type thermocouples directly placed on the specimens, the signal of which was also used to control the three-zone vertical furnace used for the test.

Attention was paid to avoid excessive holding time in the furnace before testing, in order to limit microstructural changes. The heating time was set at approximately 30-40 min (including $10 \mathrm{~min}$ holding at the test temperature, as required by the reference standard) and it was shortened for the tests at the highest temperatures. These times were the minimum possible to avoid overshooting, i.e., to exceed the set temperature during the heating stage of the test, a risk that is higher at moderate than at high set temperatures. Tensile testing was carried out in displacement control. The displacement rate was fixed at $0.012 \mathrm{mms}^{-1}$ for all testing temperatures, with the target strain rate in the plastic range of 
$2.5 \times 10^{-5} \mathrm{~s}^{-1}$, corresponding to range 2 in CEN ISO 6892-2 standard for high-temperature tensile tests [16]. Specimen elongation was measured by fixing the extensometric system to the loading pins and reading the relative displacement of pins by Linear Variable Differential Transducers. A reference length close to $60 \mathrm{~mm}$ was calculated as suggested by the above standard and used in order to estimate the strain values. Elongation (A\%) and reduction of area (RA\%) at rupture were estimated on the basis of changes in the specimen gauge length and in the cross-section. The area of the latter was approximated to remain rectangular at the end of the tests. At high temperatures, the material ductility reached very high values and tests were interrupted at about $35 \%$ strain, when the extensometric system limit was reached.

\subsection{Analyses on Tested Specimens}

Specimens tested at room temperature (RT), 350, and $450{ }^{\circ} \mathrm{C}$ were then cut longitudinally, polished, and etched with Keller's reagent to observe microstructural features with the special aim of distinguishing the features between the most stressed and strained regions, close to final fracture, and those in gripping ends where no load was applied. The metallographic samples were then observed by means of optical microscope (OM, Aristomet, Leitz, Wetzlar, Germany) and scanning electron microscope (SEM, EVO50, Carl Zeiss AG, Oberkochen, Germany). In the latter case, energy-dispersive X-ray microanalyses (EDX, OXFORD Instruments, Adingdon, UK) were also performed, using OXFORD INCA software for microanalyses. The size of the $\alpha$-Al grains was estimated with optical microscopy at low magnification, covering an area of $0.01 \mathrm{~mm}^{2}$ and analyzing three distinct regions of the sample. SEM fractographic analyses were carried out combining secondary electrons and backscattered electrons probes to highlight the correlation between morphological features and intermetallic particles.

Vickers hardness tests were performed on the above samples in the regions of the gripping ends. Test were done according to ISO 6507-1:2005 standard on a VMHT30 microindenter (Leica, Wien, Austria), with a 19.6-N load applied to the indenter for $15 \mathrm{~s}$. Five indentations were made for each experimental condition. These tests aimed to evaluate the effects brought about by aging for about 20-30 $\mathrm{min}$ (corresponding to the time spent at temperature during holding and testing).

\section{Results}

\subsection{Tensile Behaviour}

The tensile behavior of the investigated alloys was significantly affected by the testing temperature, as clearly shown in Figures 3 and 4.

At RT, the $0.2 \%$ offset yield stress (YS) and ultimate tensile strength (UTS) of the alloys fell in the 155-175 MPa and 270-290 MPa ranges, respectively. The properties of alloys A and B were close to the average values derived from previous tests at room temperature on sets of at least seven specimens carried out on the same production batches of specimens [12]. In the optimized casting process conditions, maximum deviations of $\pm 15 \mathrm{MPa}, \pm 3 \mathrm{MPa}$, and $\pm 0.2 \%$ from the average UTS, YS, and elongation at rupture (A\%) were observed from the abovementioned study [12,17]. In a related paper [13], it was demonstrated that the stress-strain response of the alloy in the uniform plastic zone is very close for specimens of the same alloy/process up to their final fracture. This latter occurred earlier in specimens containing more severe defects. This fact introduced a relatively wider scatter in the UTS data compared to that of the YS data. The limited specimens' availability prevented in the present case the repetition of tests and data scatter cannot be presented directly. Due to the progressively increasing ductility of the materials with temperature, it can be reasonably expected that the experimental scatter of tensile properties reduces as test temperature is increased.

At RT, the UTS of alloys A and B were comparable, while the lowest values were reached for alloy C. In the RT- $150{ }^{\circ} \mathrm{C}$ range, data points in Figure $3 \mathrm{a}$,b show a plateau or a slight increase at about $100{ }^{\circ} \mathrm{C}$ for YS and/or UTS. A first drop in tensile properties can be observed in the intermediate temperature 
range $\left(150-250^{\circ} \mathrm{C}\right)$, where alloy $\mathrm{C}$ mostly differentiates with respect to the other two materials in terms of UTS and displays a particularly stable resistance to plastic deformation. Above $250{ }^{\circ} \mathrm{C}$, both strength parameters decrease gradually with increasing temperature, with the highest temperature-effect on UTS. In the same temperature range, the YS and UTS are very close for the investigated alloys; the first becomes lower than $100 \mathrm{MPa}$ at about $300^{\circ} \mathrm{C}$, while UTS decreases below $100 \mathrm{MPa}$ only above $320^{\circ} \mathrm{C}$. The two strength parameters become comparable only above $350{ }^{\circ} \mathrm{C}$ and they decrease to about $10 \mathrm{MPa}$ as the test temperature is increased to $450{ }^{\circ} \mathrm{C}$. The YS and UTS data shown in Figure 3 are fitted by third-order polynomials. These fitting curves could be used as a simple empirical model to describe the strength experienced by the alloys in the temperature range up to $450{ }^{\circ} \mathrm{C}$.

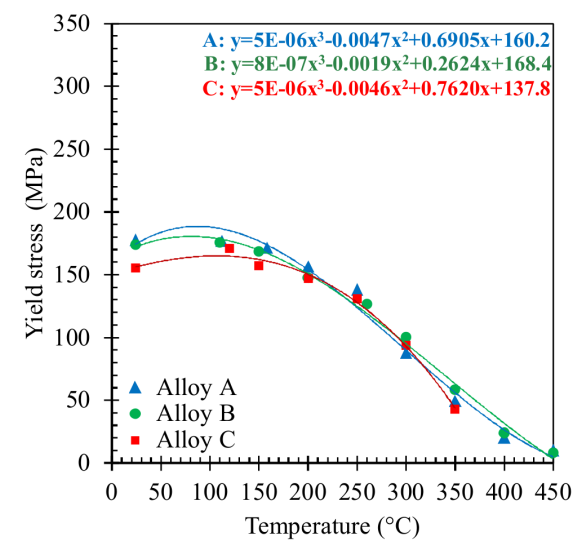

(a)

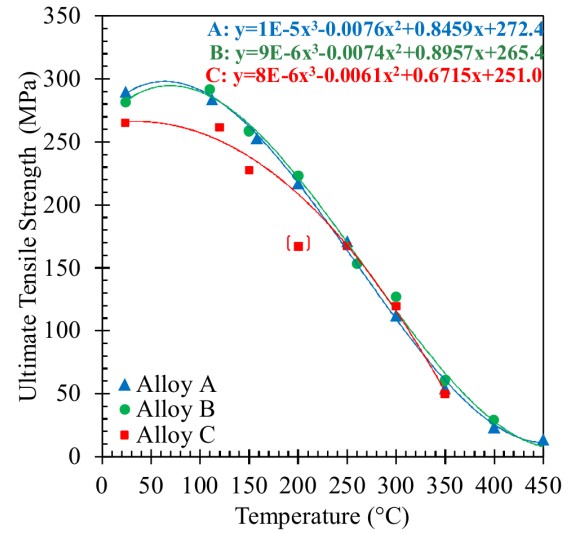

(b)

Figure 3. (a) Yield stress (YS) and (b) ultimate tensile strength (UTS) plotted as functions of test temperatures for the investigated alloys. Experimental data were fitted by third-order polynomials.

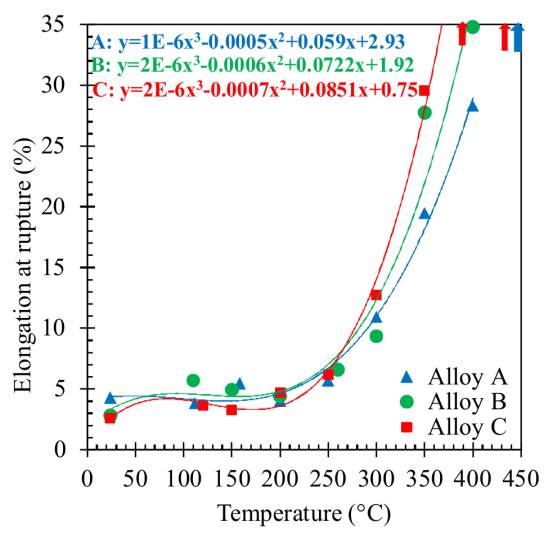

(a)

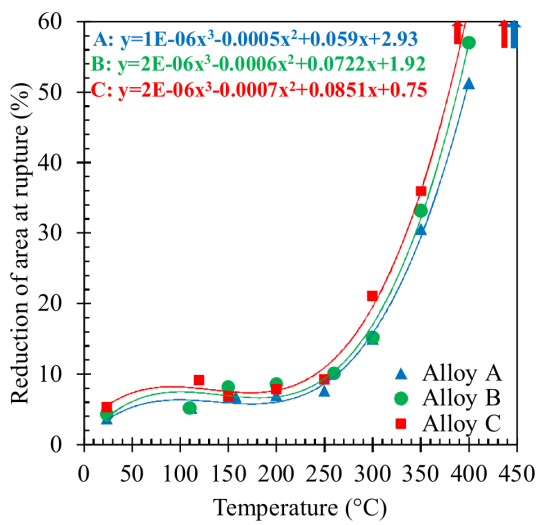

(b)

Figure 4. (a) Elongation at rupture and (b) reduction of area at rupture plotted as functions of test temperatures for the investigated alloys. Experimental data were fitted by third-order polynomials.

Test temperature also significantly affected the ductility parameters, as illustrated in Figure $4 \mathrm{a}, \mathrm{b}$ for $\mathrm{A} \%$ and $\mathrm{RA} \%$, respectively. At temperatures below $200{ }^{\circ} \mathrm{C}, \mathrm{A} \%$ remains at about $5 \%$ and $\mathrm{RA} \%$ is slightly higher. Both ductility indexes do not show significant differences between the investigated alloys (up to $200{ }^{\circ} \mathrm{C}$ ). Differences could be partly hindered by experimental scatter involved in measurements of small elongation of the broken gauge lengths. Above $250{ }^{\circ} \mathrm{C}$, the ductility rapidly increases and above $450{ }^{\circ} \mathrm{C}$ it exceeds $35 \%$ for all of the experimental alloys. In the range of $250-450{ }^{\circ} \mathrm{C}$, alloys $\mathrm{C}$ and $\mathrm{A}$ display the highest and lowest increase of ductility, respectively.

As conducted for the strength properties, a third-order polynomial fitting was adopted for the ductility as well. At high temperatures, the alloys can be easily ranked in terms of ductility, where the 
fitting lines could be actually used to describe changes of both the ductility parameters induced by temperature.

The mechanical behavior of the alloy can be further described by their flow curves. The terms of true stress vs. true plastic strain correlation was modeled by means of the Ramberg-Osgood relationship between true plastic strain $\varepsilon_{p, t}$ and true stress $\sigma_{t}[18]$ :

$$
\sigma_{\mathrm{t}}=K_{T} \times\left(\varepsilon_{\mathrm{p}, \mathrm{t}}\right) n_{T}
$$

where the constants $K_{T}$ (strength coefficient) and $n_{T}$ (strain hardening coefficient) are derived for each test by fitting experimental data in the engineering stress range from YS to UTS. The temperature dependence of these material parameters is shown in Figure 5. Different from the trends observed at low temperatures for YS and UTS, the strength coefficient monotonically decreases as the test temperature increases. Apart from room temperature, where alloy A displays the lowest $K_{T}$ value, in the intermediate temperature range $\left(110-250^{\circ} \mathrm{C}\right)$ the lowest values are calculated for alloy $\mathrm{C}$.

As far as the strain hardening is concerned, the alloy chemistry seems to play a clear role only at room temperature. The strain hardening coefficient reduces as the temperature increases up to about $350^{\circ} \mathrm{C}$, where the trend changes.

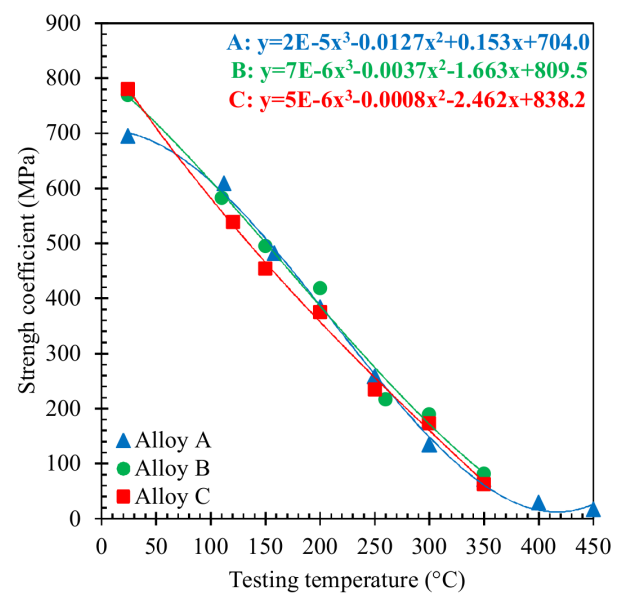

(a)

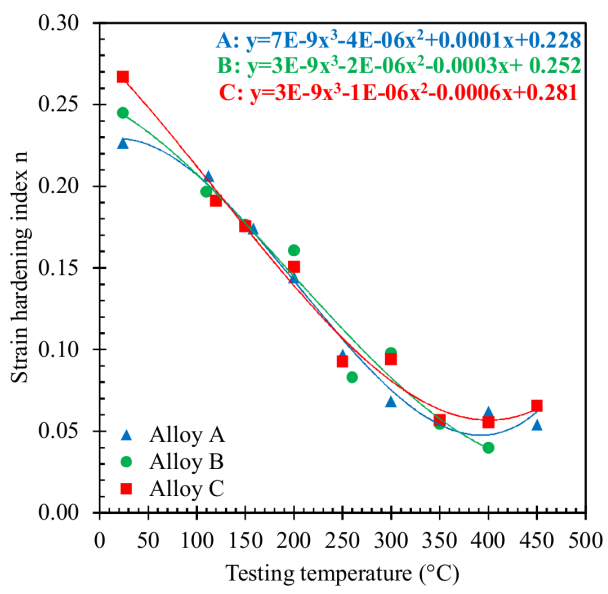

(b)

Figure 5. (a) Strength coefficient $K_{T}$ and (b) strain hardening coefficient $n_{T}$ plotted as functions of test temperatures for the investigated alloys. Experimental data were fitted by third-order polynomials.

\subsection{Hardness Testing}

The microhardness evolution as a function of holding temperature in unloaded regions of tested specimens is presented in Figure 6. A similar trend is displayed by the three materials as the test temperature rises. In the $100-150{ }^{\circ} \mathrm{C}$ range a slight decrease of hardness can be noticed with respect to room temperature. This behavior is compatible both to relieving effects of residual stresses induced by the manufacturing process [19] and to the loss of solute atoms and relative strengthening from the matrix, not fully balanced by particle strengthening.

The second feature of the common trend of the three alloys is a hardness peak between 200 and $250^{\circ} \mathrm{C}$ followed by the third feature measured above $250^{\circ} \mathrm{C}$, i.e., a monotonic decrease. The differences between the three alloys are more evident than those displayed by the strength properties YS and UTS. In the whole investigated temperature range, alloys $A$ and $C$ were clearly the hardest and softest materials, respectively. Further, material softening is anticipated in alloy $C$, for which the onset of peak appears to be shifted at higher temperatures. The hardness peaks are reasonably in the $250-300{ }^{\circ} \mathrm{C}$ range, with peak hardness and temperature increasing with the $\mathrm{Cu}$ content of the alloys. 


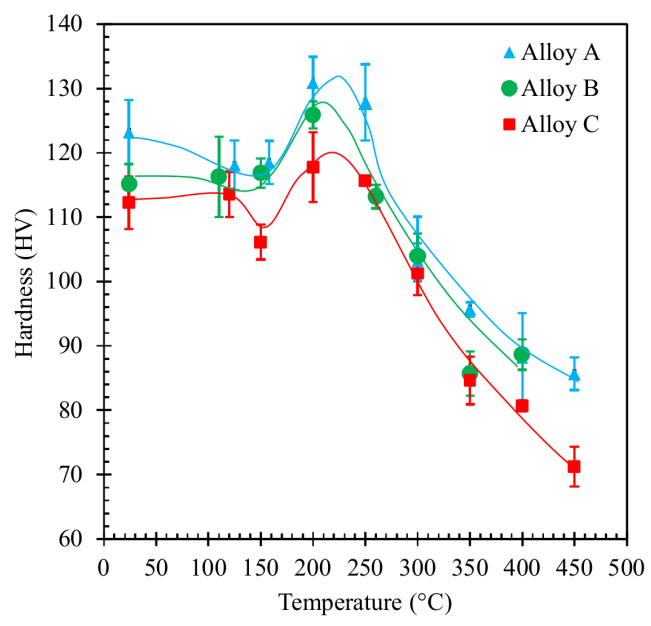

Figure 6. Microhardness of the investigated alloys measured at room temperature in unloaded zones of the specimen after tensile testing at different temperatures.

\subsection{Microstructural Observations}

The microstructure of the alloys is reported in in Figure 7. It is made of relatively small globular-dendritic grains of aluminum solid solution $\left(\mathrm{Al}_{\mathrm{ss}}\right.$ phase, light gray in micrographs in Figure 7$)$ surrounded by the eutectic structure (grey in Figure 7) characterized by fine Si particles. A relatively thick sound layer is found starting from the surface of castings while trapped air/gas porosity is concentrated in the central part of the specimens (Figure 2). The volume fraction occupied by $\mathrm{Al}_{\mathrm{ss}}$ grains varied within different regions of the samples, being $62 \pm 5 \%$ in alloy $A$ and $57 \pm 6 \%$ in both alloys $\mathrm{B}$ and $\mathrm{C}$. The size of $\mathrm{Al}_{\mathrm{ss}}$ grains varied slightly for the three materials. Details for alloys $\mathrm{A}$ and $\mathrm{B}$ are described in Reference [12].

Particles of the primary Fe-containing $\alpha$-phase, usually referred to as sludge (pointed out by the arrows in Figure 7), are observed in all of the diecast alloys, although with different features. They are coarse in alloy A (typically in the range of 15-20 $\mu \mathrm{m}$ ), and their average size decreases in alloy B and then further in alloy C. Alloy B is also characterized by the lowest volume fraction of these sludge particles.

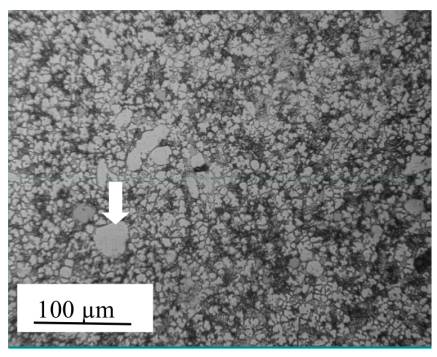

(a)

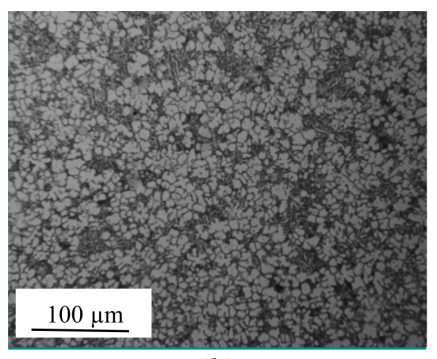

(b)

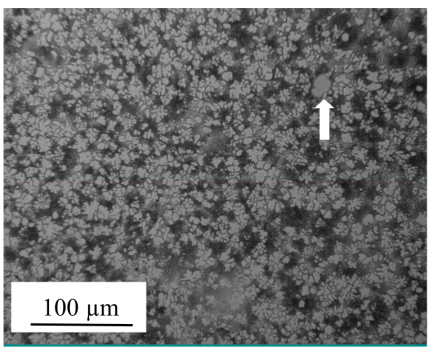

(c)

Figure 7. Microstructures of the investigated alloys in the as-diecast condition: (a) alloys A; (b) B; and (c) C.

The OM observations of the specimens after testing at room temperature and $350{ }^{\circ} \mathrm{C}$ are presented in Figure 8. At room temperature, the fracture surface lays within the relatively thin eutectic structure, at the interface between the eutectic and a slightly deformed $\mathrm{Al}_{\mathrm{ss}}$ phase. This also intercepts coarse sludge particles, which also are fractured even when their position is far from the fracture surface. In specimens tested at higher temperatures, the microstructural rearrangement corresponding to a larger plastic strain was more evident. The $\mathrm{Al}_{\mathrm{ss}}$ grain deformation increased from alloy $\mathrm{A}$ to alloy C. At this temperature, the fracture path remained within the eutectic structure. SEM observations 
revealed the presence of different intermetallic particles, on which EDX point microanalyses were performed. Representative microanalyses are here proposed in Table 2. It is worth mentioning that under the standard conditions for SEM microanalyses of Al-Si alloys, the depth of the interaction volume between the electron beam and the analyzed particles is about $1.5 \mu \mathrm{m}$ (neglecting differences among alloying elements) [20] and a similar size can be considered on the interaction surface. Consequently, the results of the point microanalyses of the intermetallic particles give an intermediate composition between the matrix and the particles rather than the composition of the latter.

Table 2. EDX (energy-dispersive X-ray) microanalyses (in mass \%) of points highlighted in the micrographs of Figure 9.

\begin{tabular}{ccccccccccc}
\hline Alloy & Figure & Point & Si & Fe & Cu & Mn & Mg & Cr & Ni & Al \\
\hline A & 9c & A & 4.06 & 1.59 & 5.50 & - & - & - & & Bal \\
A & 9c & B & 8.57 & 16.07 & 4.94 & 4.85 & - & 1.20 & & Bal \\
A & 9c & C & 35.81 & 2.90 & 22.04 & - & 1.18 & & 0.81 & Bal \\
B & 9f & A & 8.54 & 5.39 & 13.27 & - & - & - & - & Bal \\
B & 9f & B & 8.82 & - & 24.95 & - & - & - & - & Bal \\
B & 9f & C & 4.35 & - & 25.4 & - & - & - & 2.18 & Bal \\
C & 9g & A & 11.59 & 12.14 & 0.61 & 4.85 & - & 1.17 & - & Bal \\
\hline
\end{tabular}

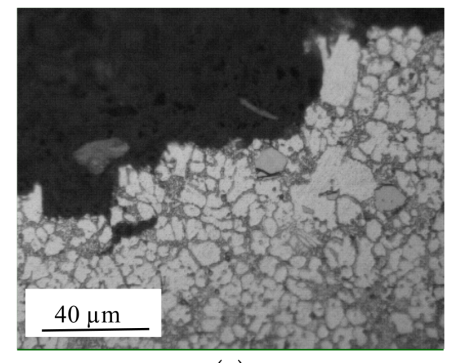

(a)

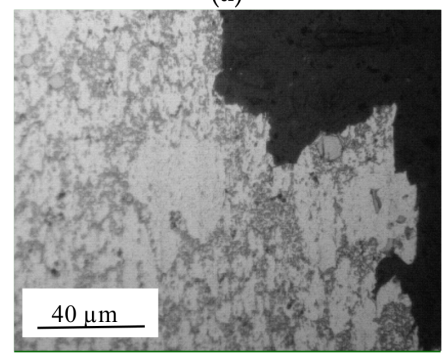

(d)

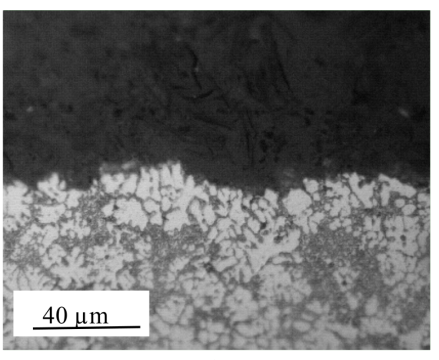

(b)

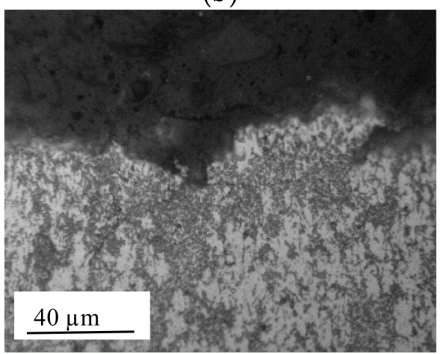

(e)

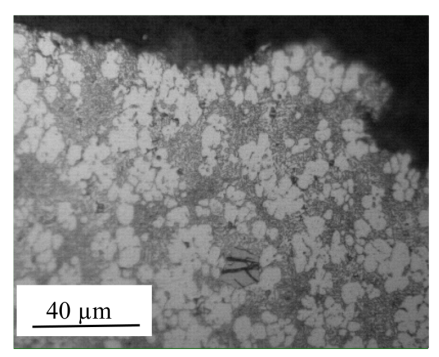

(c)

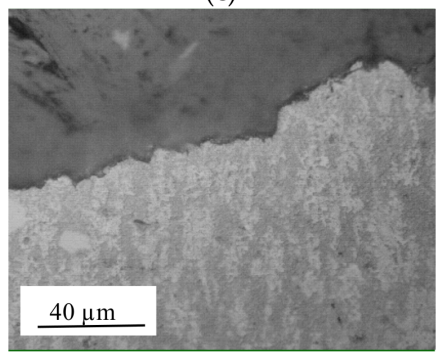

(f)

Figure 8. Representative metallographic sections close to the fracture surface of specimens tested at $(\mathbf{a}-\mathbf{c})$ room temperature and $(\mathbf{d}-\mathbf{f}) 350^{\circ} \mathrm{C} .(\mathbf{a}, \mathbf{d})$ alloy $\mathrm{A} ;(\mathbf{b}, \mathbf{e})$ alloy $\mathrm{B} ;(\mathbf{c}, \mathbf{f})$ alloy $\mathrm{C}$.

In alloy A (Figure 9a-e), the coarse polygonal sludge particles have a chemical analysis roughly corresponding to $\mathrm{Al}-18 \mathrm{Fe}-10 \mathrm{Si}-8.0 \mathrm{Mn}-4 \mathrm{Cr}$, with a comparatively smaller amount of $\mathrm{Cu}$. In this alloy, sludge particles are surrounded by an elongated $\mathrm{Al}_{2} \mathrm{Cu}$ phase (point $\mathrm{C}$ in Figure $9 \mathrm{c}$ ) and seldom by finer Fe-rich particles containing the same alloying elements. $\mathrm{Cu}$-containing particles are mainly of the $\mathrm{Al}_{2} \mathrm{Cu}$ phase, but occasionally $\mathrm{Mg}$ or $\mathrm{Ni}$ can be detected in them. Cu-rich particles appear either in globular or elongated morphologies, in the latter case underlying grains and surrounding the smallest, secondary $\alpha$-particles (as in point B in Figure 9c). In the same alloy A, the amount of the brightest $\mathrm{Cu}$-rich particles tends to reduce as the test temperature is increased, particularly in the temperature range from 350 to $450{ }^{\circ} \mathrm{C}$. At this last temperature, high-magnification images revealed the presence of globular eutectic Si particles (Figure 9e). 


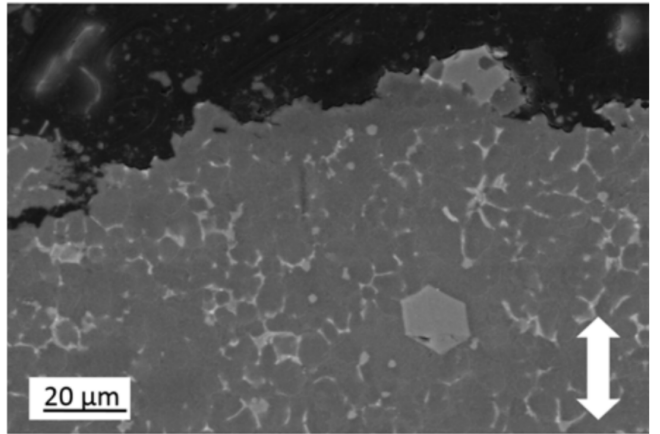

(a)

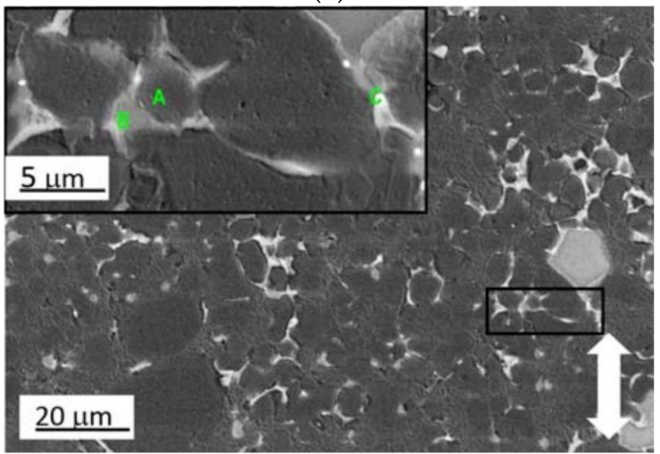

(c)

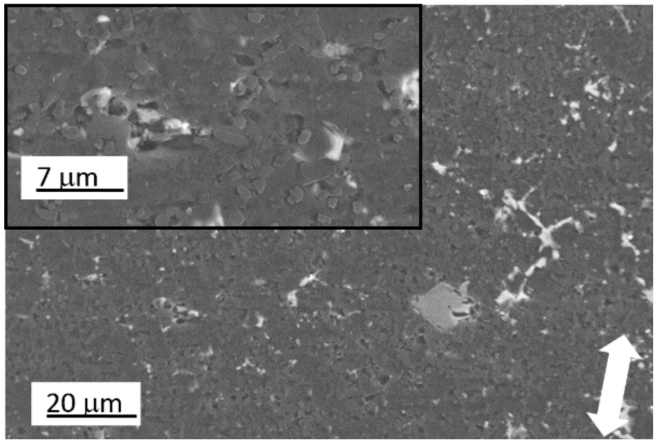

(e)

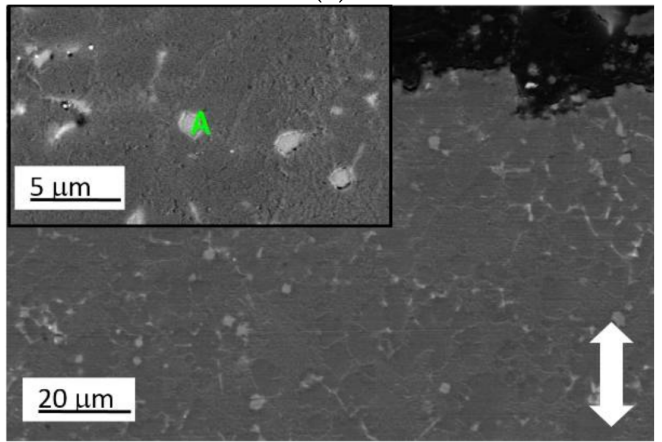

$(\mathbf{g})$

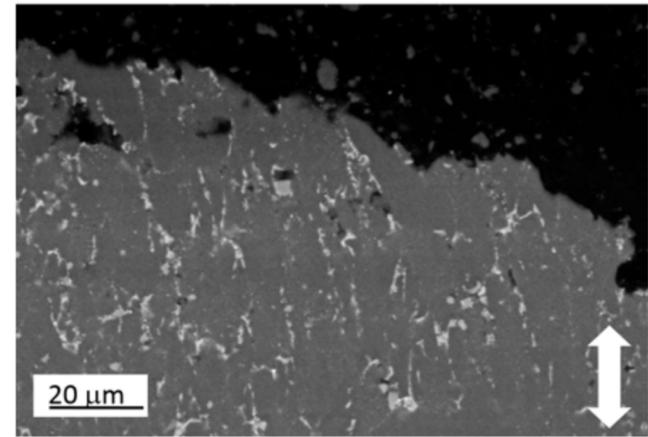

(b)

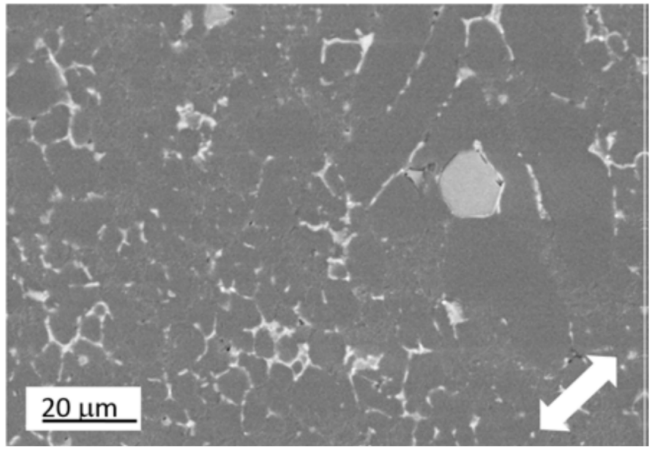

(d)

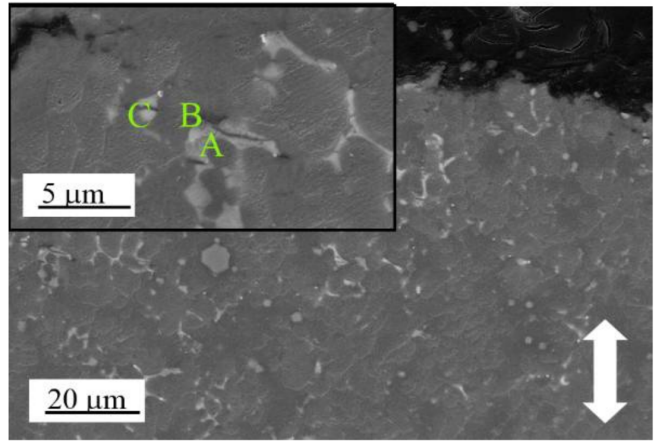

(f)

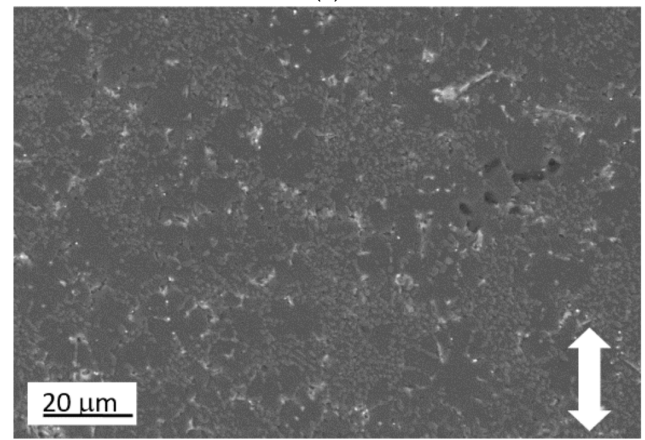

(h)

Figure 9. Representative SEM-BSE (backscattered electrons) micrographs of the longitudinal metallographic sections of tensile tested specimens taken close to the final fracture section or $5 \mathrm{~mm}$ away from it. (a-e): alloy A tested at $25^{\circ} \mathrm{C}(\mathbf{a}, \mathbf{c}), 350{ }^{\circ} \mathrm{C}(\mathbf{b}, \mathbf{d})$, and $(\mathbf{e}) 450{ }^{\circ} \mathrm{C}$; (f) alloy B tested at $25^{\circ} \mathrm{C}$; (g) alloy $\mathrm{C}$ tested at $25{ }^{\circ} \mathrm{C}$; (h) alloy $\mathrm{C}$ tested at $450{ }^{\circ} \mathrm{C}$. White arrows display the loading direction. $\mathrm{Cu}$-rich phase particles are the brightest, $\alpha$-particles have an intermediate gray color.

As the amount of $\mathrm{Cu}$ decreases from alloy $\mathrm{A}$ to alloy $\mathrm{C}, \mathrm{Cu}$-containing particles, mainly surrounding homogeneous grains, can be observed in lower amount and size (compare Figure 9a with 
Figure 9f,g). As far as Fe-containing intermetallic particles are concerned, in addition to the coarse $\alpha$-particles previously described, smaller particles with similar a morphology, possibly a secondary $\alpha$-family, was also observed in alloys (points A in Figure 9f,g), with their average size being lower than that observed in alloy A.

SEM analyses of tested samples confirm that at room temperature the fracture of all of the alloys occurred in the interdendritic regions where, in addition to $\mathrm{Al}_{\mathrm{ss}}$ and eutectic $\mathrm{Si}$, other coarse and brittle intermetallic phases were located (Figure 9a,f,g). Micrographs taken using a backscattered electrons (BSE) probe revealed the presence of early decohesions at the matrix-particle interfaces.

At $350{ }^{\circ} \mathrm{C}$, the greater ductility of the matrix promoted the reorientation of elongated particles along the loading direction. Strain also caused further fragmentation of interdendritic particles, specifically in the case of coarse particles. The result was that at this temperature, the alloys displayed higher strains and concurrently withstood higher amounts of damage (i.e., decohesions) before the final fracture (compare Figure 9a,b).

Specimens tested at the highest temperature exceeded strains of 35\% without reaching the final fracture. However, they displayed some evidence of microstructural damage in their gauge length, as shown in Figure 9e,h, which refer to alloys A and C, respectively. The increased matrix ductility with respect to $350{ }^{\circ} \mathrm{C}$, the presence of spheroidized Si particles, and the reduction of the amount and size of the $\mathrm{Cu}$-containing particles prevented early fracture, which occurred in any case at or within intermetallic particles, starting with the coarser ones (Figure 9e). The microstructural damage observed in alloy $\mathrm{C}$ is less marked than that in alloy $\mathrm{A}$, as a result of the lower amount and smaller size of particles from which damage starts. Fracture surface analyses, here reported in Figure 10, confirmed that in all cases fracture was of a ductile type, with dimples of the $\mathrm{Al}_{\mathrm{ss}}$ phase often formed at intermetallic particles (brighter in BSE fractographs) as well as at the eutectic silicon. The increased local deformation of the matrix at high temperatures can be observed by comparing Figure 10a,b for the alloy B, while the lower ductility of alloy A and the presence in it of a higher amount of coarser particles can be observed in Figure 10c.

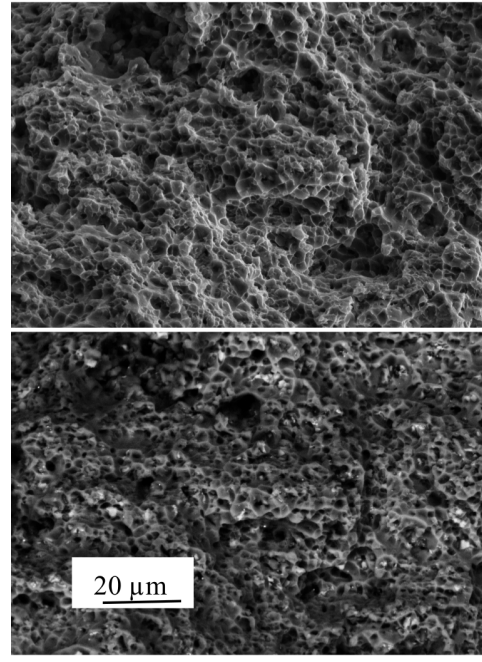

(a)

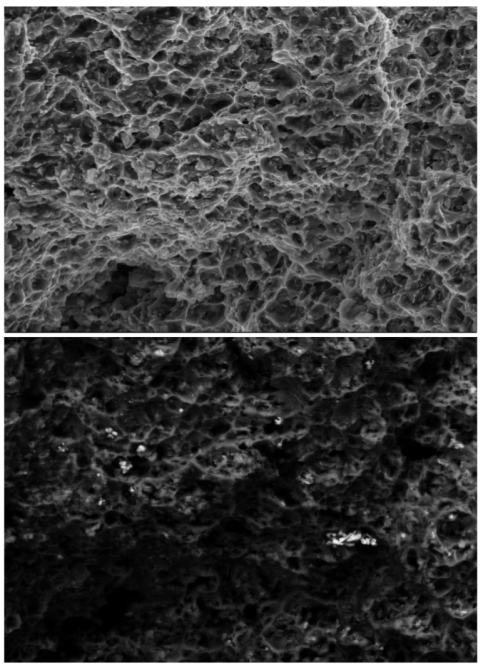

(b)

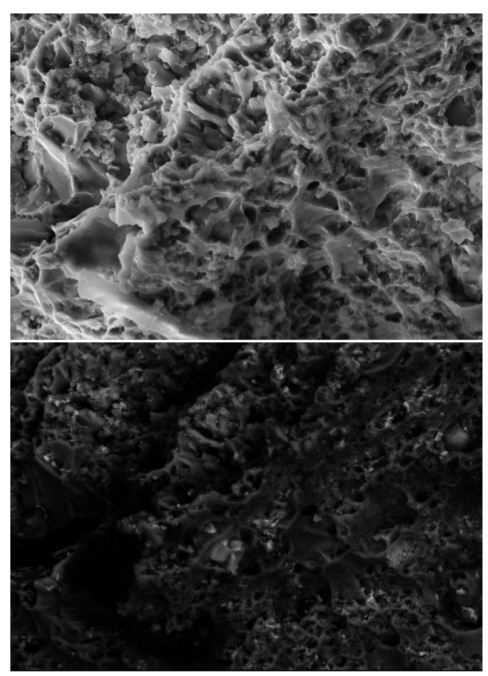

(c)

Figure 10. Representative fractographs (all at the same magnification) of tensile tested specimens: (a) alloy B, $25{ }^{\circ} \mathrm{C}$; (b) alloy B, $350{ }^{\circ} \mathrm{C}$; (c) alloy A, $350{ }^{\circ} \mathrm{C}$. For each alloy the top fractograph was taken by a secondary electrons probe, while the bottom fractography employed backscattered electrons to highlight the presence of intermetallic phases. 


\section{Discussion}

At temperatures above $200^{\circ} \mathrm{C}$, the tensile strength (YS and UTS) of the investigated alloys were severely affected by temperature, and less by chemical differences. These, on the other hand, had clear effects on ductility (Figure 4), which was particularly high in alloy $\mathrm{C}$ above $250{ }^{\circ} \mathrm{C}$. The greatest ductility of this alloy was also demonstrated by the stress-strain curve, which displayed the relative maximum below $150^{\circ} \mathrm{C}$. Microstructural observations suggested a damage mechanism where coarse intermetallic particles (including primary $\alpha$-phase), eutectic, as well as the deformability of $\mathrm{Al}_{\mathrm{ss}}$ grains play an important role, with clear differences in the investigated alloys according to the testing temperature. The deformability of $\mathrm{Al}_{\mathrm{ss}}$ grains was particularly sensitive to the age-hardening response of the alloys, as deduced from hardness of the tested specimens, which differentiate the alloys' behavior more than the tensile strength parameters.

The effects of alloy chemistry on the short-term high-temperature properties of Al-Si-Cu alloys should thus be mainly attributed to coarse intermetallic phases resulting from alloy solidification, eutectic, as well as the amount of intragranular strengthening particles, which mainly precipitate during high temperature exposure prior or during testing. Due to the relatively wide and partly overlapping elemental ranges according to EN 1706 standard (see Table 1), the actual rather than the nominal alloy chemistry has to be taken into account to verify compositional effects. In the present case, the Si content, known to affect the amount of the most significant eutectic phase, was slightly higher in the alloy nominally containing 11 mass \% Si than in that with a nominal content of 12 mass $\%$. On the other hand, the amount of $\mathrm{Cu}$, related to the possibility to age-harden alloys, decreased from alloy $\mathrm{A}$ to $\mathrm{C}$, according to their nominal composition.

Considering the $\mathrm{Zn}$ content, due to the low amount of $\mathrm{Mg}$ in the alloys (0.22-0.25 mass \%), it could not induce age-hardening effects, but it remained in the Al-rich solid solution ( $\mathrm{Al}_{\mathrm{ss}}$ phase) $[1,21]$. The beneficial, even if slight, effect of Zn on the tensile properties at RT decreased from alloys B to A and C. Further, strengthening by $\mathrm{Zn}$ was not significantly affected by exposure at higher temperatures, where $\mathrm{Zn}$ solubility in $\mathrm{Al}_{\mathrm{ss}}$ was greater than that at $\mathrm{RT}$. The role of this element will thus not be discussed further in this paper.

The same decreasing trend from alloys B to A and C could be observed for iron content, although in a quite narrow range of $0.721-0.889$ mass $\%$. Iron is known to govern material ductility by affecting the amount of Fe-containing particles, as well as their shape and size. Minor elements such as $\mathrm{Mn}, \mathrm{Cr}$, and $\mathrm{Ni}$ can also play an important role in the amount, morphology, and distribution of intermetallic particles, specifically in many Fe-containing phases reported in the literature [21-25]. The composition and presence of Fe-containing phases will be discussed later, as related to thermodynamic simulation results. $\mathrm{Ni}$, which gives the possibility to form some intermetallic phases in the alloys of interest (see the review work by Rana et al. [22]) was found in a relatively similar amount in all of the investigated alloys and reasonably plays no significant role in differentiating the alloy microstructures and properties. Thus, the effect of Ni will also not be further taken into account. Similarly, the effects of Ti, known as a refining element, and of $\mathrm{Sn}$, whose addition is reported to improve alloy fluidity but also induce soldering effects [1], will not be considered hereafter.

\subsection{Thermodynamic Simulations and Microstructures/Properties at Room Temperature}

Thermodynamic simulations were carried out to verify the effect of the alloy composition on phases formed during solidification and on those related to precipitation strengthening during the following exposure at high temperatures before and during tensile testing. The alloy composition was simplified, neglecting the presence of $\mathrm{Ti}, \mathrm{Sn}, \mathrm{Pb}$, and other minor elements and impurities, as previously discussed.

The solidification was simulated under Scheil-Gulliver (SG) assumptions (no back-diffusion in solid phases) and assuming intermetallic phases of fixed chemical composition. In Al-Si-Mg alloys, the SG approach has already been proved by Dorè et al. [26] to be very close to the solidification path under more complex assumptions in the case of solidification times of $10 \mathrm{~s}$, which are higher than 
the solidification time employed in the present case. The same SG approach has been often applied for other alloys since it is able to account for a wider solidification range and a higher number of intermetallic phases generally observed in casting alloys with respect to the simplified solidification description in equilibrium conditions [27,28].

A summary of the main interest results for the present study is plotted in Figure 11. They will be discussed below, comparing them, whenever possible, to the experimental results and/or to literature data. The liquidus temperature $\left(T_{\text {liq }}\right.$ ) decreased progressively from alloy $\mathrm{A}$ to alloy $\mathrm{C}$, and the solidification temperature range reduced correspondingly. By following the solidification sequence, the first stage led to the formation of the primary $\alpha$-phase in all cases, the so-called sludge, a common feature of the solidification sequence of the three alloys. Primary $\alpha$ formed at highest temperature range in alloy A $\left(629-593^{\circ} \mathrm{C}\right)$, and in the lowest and shortest range for alloy $\mathrm{C}\left(611-585^{\circ} \mathrm{C}\right)$.

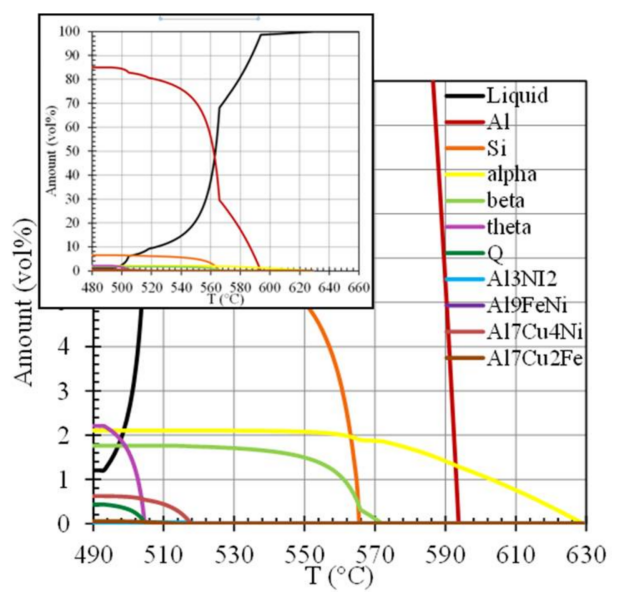

(a)

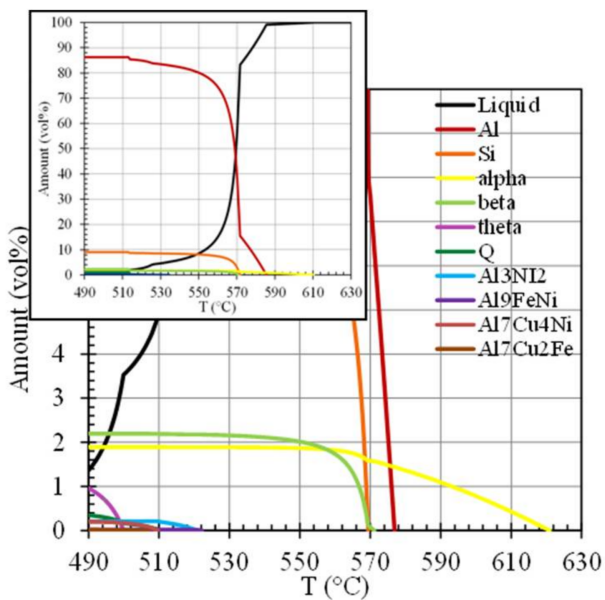

(b)

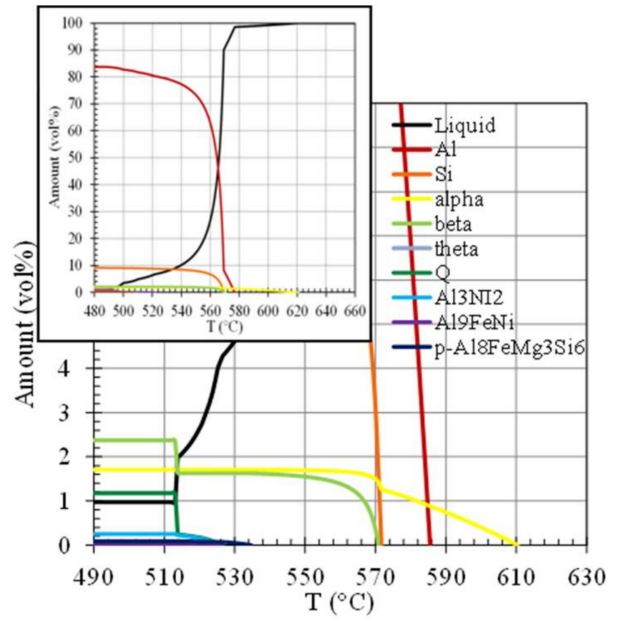

(c)

Figure 11. Modeled evolution of the amount of phases during non-equilibrium solidification. (a) Alloy $\mathrm{A}$; (b) alloy B; and (c) alloy $\mathrm{C}$. For each alloy the macroscopic changes related to liquid and $\mathrm{Al}_{\mathrm{ss}}$ are visible in the top-left-side of the plot, whose y-scale is extended to $100 \mathrm{vol} \%$.

In the literature, the presence of sludge is often related to the sludge factor (SF), an Fe equivalent calculated as a weighted sum of $\mathrm{Fe}, \mathrm{Mn}$, and $\mathrm{Cr}$, whose weight factors are 1, 2, and 3, respectively, as in Reference [29]. The SF of the present materials is 1.57 for both alloys A and B, and 1.32 for alloy C. Further, experimental observations by Ferraro et al. [25] showed that the size of sludge particles increases as the Fe and Mn contents increase, corresponding to the increase of the temperature for the onset of solidification, as observed experimentally for Fe by Shabestari [29] and from computed 
phase diagrams for Mn by Cao [30]. Thus, on the basis of SF and temperature ranges for the first stage of solidification, alloys $\mathrm{A}$ and $\mathrm{B}$ should be characterized by the highest amount of the primary sludge particles, slightly coarser in alloy $\mathrm{A}$, while alloy $\mathrm{C}$ should be characterized by a minor amount of primary $\alpha$-particles-both features confirmed here by microstructural observations.

A second step of solidification can be considered to last up to the onset of eutectic formation, predicted at 566,569 , and $572{ }^{\circ} \mathrm{C}$ for alloys $\mathrm{A}, \mathrm{B}$, and $\mathrm{C}$, respectively. Most of this temperature range is characterized by the transformation of liquid into $\mathrm{Al}_{\mathrm{ss}}$ and $\alpha$-phase. At the end of this solidification stage, the amount of $\mathrm{Al}$, in the form of homogeneous $\mathrm{Al}_{\mathrm{ss}}$ grains, is nearly $30,8.7$, and $15.5 \mathrm{vol} \%$ for alloys A, B, and C, respectively, thus with a significant difference for the two alloys with close $\mathrm{Si}$ content, which is different from present experimental observations. Experimental results also led to higher amounts of $\mathrm{Al}_{\mathrm{ss}}$, partly probably due to difficulties in attributing $\mathrm{Al}_{\mathrm{ss}}$ to homogeneous grains rather to eutectic, partly due to the shifting of the eutectic composition to higher Si contents caused by alloy compression acting during solidification, as explained by Kaufman et al. [27] and neglected by the applied thermodynamic model.

The predicted amounts of $\alpha$-phase formed during this second solidification step were $0.60,0.14$, and $0.38 \mathrm{vol} \%$ for alloys A, B, and C, respectively. The morphology of this phase cannot be defined by the present approach and part of it could add to primary $\alpha$-particles formed during the earlier stage. At the lowest temperatures of this range, the model predicts the concurrent formation of relatively low or no amounts of pro-eutectic $\beta-\mathrm{Al}_{5} \mathrm{FeSi}$ phase; $0.31,0.07$, and $0 \mathrm{vol} \%$ for alloys $\mathrm{A}, \mathrm{B}$, and $C$, respectively.

The third and last stage of solidification can be considered to be characterized by the concurrent formation of silicon and intermetallic phases together with the $\mathrm{Al}_{\mathrm{ss}}$, forming binary and/or more complex eutectics. The predicted amount of the Si phase at the end of solidification was close to $9 \mathrm{vol} \%$ for alloys B and C, and less than 7 vol \% in low-Si alloy A, mostly formed at the beginning of this solidification stage. The $\mathrm{Al}_{\mathrm{ss}}$ homogeneous grains and Si-containing eutectic structure will not be discussed in detail here, except to mention that minor differences in the morphology of the Si phase could be predicted as a result of similar temperatures and cooling rates.

During the first part of this stage of solidification, the amount of $\alpha$-phase further increased and stabilized, while $\beta$ also appeared in alloy C. Primary $\alpha$-particles with an average size decreasing from alloy A to $\mathrm{C}$ were experimentally observed according to their predicted nucleation and formation temperature ranges. Additionally, many $\alpha$-pro-eutectic particles of a rather polyhedral morphology were experimentally found in all of the alloys.

The observed amount of primary and secondary $\alpha$ followed the trend suggested by thermodynamic simulations, confirming at the same time other results reported in the literature. On the other hand, $\beta$-particles were detected only in exceptional cases. In addition to the possible differences of modeled and experimental solidification conditions, the predicted amount of the above Fe-containing particles could be related to simplified assumptions made about their chemistry. Their composition has been widely described in the literature [25,28-34], specifically for $\alpha$-phase, which can be written in the most general form as $\mathrm{Al}_{x}(\mathrm{Fe}, \mathrm{Mn}, \mathrm{Cr}, \mathrm{Cu})_{y} \mathrm{Si}_{z}$. In the thermodynamic software, the $\alpha$-phase is modeled as stoichiometric $\mathrm{Al}_{15}(\mathrm{Fe}, \mathrm{Mn}, \mathrm{Cr}, \mathrm{Cu})_{3.6} \mathrm{Si}_{2}$, while the $\beta$-phase is modeled as $\mathrm{Al}_{5} \mathrm{Fe}_{2} \mathrm{Si}$. During solidification, the modeled composition of the $\alpha$-phase change, as shown in Figure 12 for alloy A, with progressive relative enrichment in $\mathrm{Fe}$ and $\mathrm{Cu}$. Correspondingly, the predicted ratio between the sum of Fe and its substitutional elements and Si (all in mass \%) increased from 3.45 to 3.63. This ratio is well within the range of 3-4.5 for Fe/Si suggested for the $\alpha$-phase in Al-Si-Fe alloys by Ferdian [31], who also suggested the narrower and lower range of 1.8-2 for the $\beta$-phase. The actual composition of Fe-containing particles differed from predictions: EDX analyses of these particles confirmed the presence of substitutional elements for Fe in all particles, with $(\mathrm{Fe}+\mathrm{Mn}+\mathrm{Cr}+\mathrm{Cu}) / \mathrm{Si}$ ratios in the range of 2.8-3.2 for coarse sludge particles (Figure 9a,c) and lower (2.2-2.4) for the small particles (A in Figure 9f). This confirms that the difficulties in correct predictions of the type of Fe-containing particles in the investigated secondary alloys are at least partially related to simplified assumptions 
made about their chemistry. Even if the actual type and amount of Fe-containing phases cannot be carefully predicted, their total amount and main features, such as the coarseness of primary sludge particles in alloy A, which proved to be detrimental for its ductility, can nevertheless be derived from the thermodynamic models.

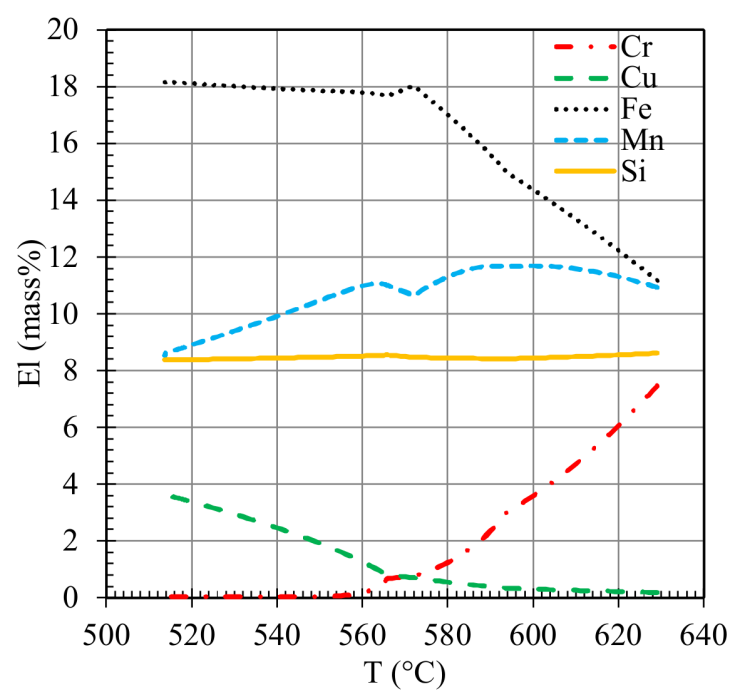

Figure 12. Predicted changes in the chemical composition of the $\alpha$-phase ( $\mathrm{Al}$ could be derived as a complement of $100 \%$ ) according to Scheil-Gulliver conditions for alloy A.

Other phases formed in a last stage of the same third solidification stage, i.e., below $\sim 530{ }^{\circ} \mathrm{C}$. According to SG assumptions, the formation of the $\theta-\mathrm{Al}_{2} \mathrm{Cu}$ phase is possible for alloys $\mathrm{A}$ and $\mathrm{B}$ ( 2.16 and $1.03 \%$, respectively), while in equilibrium conditions it occurs in all of the alloys only after the completion of solidification. Non-equilibrium solidification leads also to the presence of a quaternary Q- $\mathrm{Al}_{5} \mathrm{Cu}_{2} \mathrm{Mg}_{8} \mathrm{Si}_{6}$ phase, which is predicted in equilibrium (1.7\%) at the end of solidification only for alloy $\mathrm{C}$. Experimental observations confirmed the presence of coarse $\mathrm{Cu}$-containing particles, whose overall amount decreased with the amount of $\mathrm{Cu}$. In alloys $\mathrm{A}$ and $\mathrm{B}$, they were $\theta-\mathrm{Al}_{2} \mathrm{Cu}$ particles, which were mixed with $Q$ phase particles in alloy $C$.

Other intermetallic containing transition metals such as $\mathrm{Ni}, \mathrm{Cu}$, or Fe were found in minor amounts. No Zn-containing phase was predicted to form.

During the manufacturing process of the investigated materials, the solidification stage was followed by fast cooling up to the extraction of the thin HPDC specimens from the die, followed by slower air cooling to room temperature. According to literature [9], the cooling stage does not significantly alter the amount of phases.

Thus, at the end of solidification, the predicted microstructure in the alloys included $\mathrm{Al}_{\mathrm{ss}}$ grains, silicon, $\alpha, \beta$, and other intermetallic phases, such as $\mathrm{Al}_{2} \mathrm{Cu}, \mathrm{Q}$, and possibly minor amounts of other intermetallics. The amounts of phases different from $\mathrm{Si}$ and $\mathrm{Al}_{\mathrm{ss}}$ predicted at room temperature were 7.1, 5.9, and 3.8 vol \% for alloys A, B, and C, respectively. The overall amount of these phases, containing high atomic number elements, qualitatively observed in SEM-BSE micrographs of Figure 9 , confirmed their higher amount in alloy $\mathrm{A}$, as well as the lowest amount in alloy $\mathrm{C}$, as predicted. X-ray diffraction analyses as a means to verify the presence of phases in minor amounts in AlSi9Cu3Fe had been previously tested by some of the authors of the present paper [35], but no other phases were identified in addition to $\mathrm{Al}_{\mathrm{ss}}, \mathrm{Si}, \alpha$, and $\theta-\mathrm{Al}_{2} \mathrm{Cu}$. Therefore, the results would not reasonably supply different results for the other two investigated alloys.

The fast cooling during and after solidification also affected the composition of $\mathrm{Al}_{\mathrm{ss}}$, which at room temperature is a supersaturated solid solution. The degree of supersaturation was greater in the alloy containing the highest amount of $\mathrm{Cu}$ at the end of solidification $[3,36]$. The time spent to conduct 
the manufacturing process and mechanical testing of the cast specimens was sufficiently long to cause natural aging in these age-hardenable alloys. A careful prediction of the microstructural changes taking place within $\mathrm{Al}_{\mathrm{ss}}$ grains is not easy. Neglecting the amount of $\mathrm{Cu}$ inside coarse particles, that of intragranular nanometric particles formed during this stabilization period, could be roughly correlated to the equilibrium amount of the stable phases belonging to the actual precipitation sequence: $\theta-\mathrm{Al}_{2} \mathrm{Cu}$ or $\mathrm{Q}-\mathrm{Al}_{5} \mathrm{Cu}_{2} \mathrm{Mg}_{8} \mathrm{Si}_{6}$. The amounts of the latter phase calculated in equilibrium at room temperature were in the range $0.71-0.81 \mathrm{vol} \%$, while those of $\theta-\mathrm{Al}_{2} \mathrm{Cu}$ were $4.3,2.3$, and less than $1 \%$ for alloys $\mathrm{A}$, $\mathrm{C}$, and B, respectively. Considering the amount of coarse particles in the above phases stable at RT, the expected response to natural aging is strongest in alloy $\mathrm{A}$ and mildest in alloy $\mathrm{C}$.

A direct confirmation of the presence of the strengthening particles of nanometric size by TEM observations was outside the scope of the present work. Nevertheless, the higher RT yield strength of the alloy with the highest $\mathrm{Cu}$, notwithstanding its lowest amount of eutectic structure, can be considered as an indirect proof of this.

In alloy $\mathrm{A}$, the beneficial effect of the highest volume fraction of fine strengthening particles, the size of which can be assumed to be similar in the three naturally aged alloys, prevailed over other microstructural effects, leading to the highest strength at RT. The alloy hardness was also improved by the relevant amount of the coarse and hard intermetallic phases formed during solidification. Even if no critical plate-like or acicular morphology was noticed for these phases, the combination of their higher amount and bigger size is responsible for the lowest ductility of alloy A, for which stress-strain curves do not display the relative maximum below $200{ }^{\circ} \mathrm{C}$.

\subsection{High-Temperature Mechanical Behaviour and Microstructural Features}

When addressing the high-temperature behavior of the investigated alloys, the considerations of the phases formed during solidification and stabilization at room temperature should be coupled to the microstructural modifications taking place during heating and holding time prior or during to the test to explain the high-temperature tension tests results and the hardness of the pulled specimens. These microstructural modifications will be discussed here in the three temperature ranges suggested by hardness test results; RT- $150{ }^{\circ} \mathrm{C}, 150-250{ }^{\circ} \mathrm{C}$, and $250-450{ }^{\circ} \mathrm{C}$.

As the test temperature increased up to $150^{\circ} \mathrm{C}$, the tensile properties showed a plateau or a slight increase in YS and/or UTS followed by slight decrease at the highest temperature, with a concurrent slight increase in elongation and decrease of hardness that, at $150{ }^{\circ} \mathrm{C}$, was more pronounced for alloy C. This behavior, recently reported by Czerwinski [37] for isochronal tests on A380 alloy, is compatible with stress relief occurring at these low temperatures. While heating up to these temperatures, no drastic evolution of intragranular precipitates in the previously stabilized condition can be reasonably expected, nor compositional change in intermetallic phases containing low-diffusivity elements. In this temperature range, the combination of strength and ductility properties does not fundamentally change with respect to that at room temperature. The most brittle alloy A reached UTS values comparable to those of alloy B, characterized by a lower YS. Opposite trends, in terms of hardness, strength, and ductility, were noticed for alloy $\mathrm{C}$, characterized by a low amount of $\mathrm{Cu}$ and a $\mathrm{Si}$ content close to that of alloy B, but also by the shortest solidification range, for which microstructural investigations confirmed the predicted low amount of coarse Fe- and $\mathrm{Cu}$-containing intermetallic particles. At the microscopical level, the fracture mode that can be derived from Figures 8-10 was of ductile type in all the of alloys/temperatures, with dimples in many cases located at intermetallic phases, the coarser of which (sludge particles) often fractured. A progressive increase of the ductility of these alloys with temperature can be correlated to the microstructural changes taking place within the matrix: the formation of intermetallic particles and then their coarsening/dissolution, as well as changes in the amount of the intermetallic phases.

In the second temperature range, i.e., from about 150 to $250{ }^{\circ} \mathrm{C}$, the importance of $\mathrm{Cu}$ as an element affecting age-hardenability became evident, specifically in the hardness of pulled specimens, and partly on the yield strength that, at $250{ }^{\circ} \mathrm{C}$, did not follow the simple trend suggested by the 
third-order polynomial fitting lines in Figure 3a. The strengthening effects of precipitates formed in this temperature range and the concurrent reduction of the matrix ductility were hindered in UTS and ductility indexes, and most significantly affected by test temperature. The effect on the strain-hardening index was even more critical to detect since the formation of precipitates reduces strain hardening, similar to an increased test temperature.

As the test temperature increased, the amount of $\mathrm{Al}_{2} \mathrm{Cu}$ in equilibrium progressively reduced as the solvus temperature was approached and the strengthening phase changes and coarsening reduced their strengthening effect. The peak of hardness values, originated by an optimal amount and size distribution of strengthening particle, was higher as the amount of $\mathrm{Cu}$ increased, but also broader due to the higher solvus temperature for the $\mathrm{Cu}$-containing phases. The initial microstructural condition of the alloys as well as the combination of heating/holding time and temperature affected the hardness peak and the mechanical properties of each alloy. In the present case, the initial alloy microstructure and precautions during the experimental testing reasonably led to strengthening effects far from the highest possible for $\mathrm{Cu}$-containing alloys, such as those attainable by a suitable combined solution treatment and artificial aging [3].

The steep reduction of hardness above the peak value and the increase in ductility can be considered as transition to the third and higher temperature range $\left(250-450{ }^{\circ} \mathrm{C}\right)$. Here, the strengthening effects of fine intragranular precipitates based on the $\theta-\mathrm{Al}_{2} \mathrm{Cu}$ sequence was rapidly lost due to the abovementioned fine particle coarsening and dissolution. Particles of the $Q$ precipitation sequence behaved similarly, but with a higher solvus temperature, as observed by Bassani et al. [38]. As a matter of fact, the calculated solvus temperature for $\theta-\mathrm{Al}_{2} \mathrm{Cu}$ and $\mathrm{Q}$ for alloy A were 409 and $477{ }^{\circ} \mathrm{C}$, respectively, while in equilibrium conditions no $\theta-\mathrm{Al}_{2} \mathrm{Cu}$ was predicted above about $225{ }^{\circ} \mathrm{C}$ in alloys B and C. The combination of a higher amount of fine precipitates possible in alloy $\mathrm{A}$ and higher solvus temperatures corresponded to a higher hardness peak temperature, as well as a more gradual hardness reduction and ductility increase above the peak. The presence of coarse $\mathrm{Al}_{2} \mathrm{Cu}$ particles was also affected by temperature and reduced progressively as the test temperature increased. Their dissolution was similarly observed above $250{ }^{\circ} \mathrm{C}$ by Zamami et al. [8] for the same alloy grade of alloy A. At the highest temperatures, Fe-containing particles can modify, too. Each particle group has its own dissolution kinetics, related to their initial size and to the alloy chemistry, which defines their equilibrium amount at different temperatures. Since these coarse particles are related to the fracture mechanism, the higher amount of stable coarser sludge particles and pro-eutectic Fe-containing intermetallic and coarse $\mathrm{Al}_{2} \mathrm{Cu}$ particles kept the ductility of alloy $\mathrm{A}$ at the lowest levels (as confirmed by fractographic and microstructural analyses), even in the high temperature range, in agreement with the findings reported by Samuel et al. [39]. The part of the thermal cycle anticipating the tensile test, specifically the holding time spent at high investigated temperatures, could alter the amount and distribution of coarse particles, thus affecting the alloy ductility but with reasonably low effects on the strength properties of the alloys.

Lastly, it is worth mentioning that creep effects can play a role on the mechanical behavior of Al-Si alloys as the temperature is increased above $100{ }^{\circ} \mathrm{C}$, resulting in a progressively more significant strain-rate dependence of the tensile properties of the alloys, as experimentally proven recently above $200{ }^{\circ} \mathrm{C}$ [8]. In the temperature range where the precipitation of strengthening phases can take place, strain rate effects are particularly difficult to predict.

\section{Conclusions}

- The short-term tensile behavior of the three investigated Al-Si-Cu alloys showed a clear decrease of tensile properties above $200{ }^{\circ} \mathrm{C}$, with a steep decrease occurring at testing temperatures between 250 and $350{ }^{\circ} \mathrm{C}$, corresponding to a significant increase in ductility.

- The tensile behavior of alloys at high temperatures can be described by $K_{T}, n_{T}$ parameters, for which simple correlations with temperature have been proposed. 
- Material hardness and ductility indexes better evidence the differences in the mechanical behavior of the different alloys and can be related to the microstructural changes taking place at the test temperatures.

- Microstructural damage mechanisms are mainly correlated, at all of the investigated temperatures, to the amount and size of secondary phases and coarse intermetallic particles. The AlSi12Cu1(Fe) alloy, characterized by a lower amount of these particles, displayed the highest ductility indexes, particularly above $300{ }^{\circ} \mathrm{C}$, when the highest ductility of its $\mathrm{Al}_{\text {ss }}$ grains combined to the lowest amount of coarse intermetallic phases characterizing this alloy.

- The hardness of specimens pulled at $150-250{ }^{\circ} \mathrm{C}$ suggests an age-hardening strengthening effect, even in the alloy stabilized at room temperature for a long time. The strengthening effect increased with the actual $\mathrm{Cu}$ content of the alloy, corresponding to a higher amount of fine particles formed within the $\mathrm{Al}_{\mathrm{ss}}$ phase. Since their evolution is highly affected by the thermal cycle of the alloy, the actual peak temperature and hardness as well as other mechanical properties in the investigated temperature range are influenced by the thermal history of the material before the tensile test.

- The presence of coarse intermetallic phases in different alloys, related to their ductility, as well as the relevance of age-hardening effects by $\theta-\mathrm{Al}_{2} \mathrm{Cu}$ and $\mathrm{Q}-\mathrm{Al}_{5} \mathrm{Cu}_{2} \mathrm{Mg}_{8} \mathrm{Si}_{6}$ precipitation sequences, related to their strength at intermediate temperatures, can be derived from the results of thermodynamic simulations.

Author Contributions: All the authors actively participated to the research: F.B. and G.T. worked on the material selection, and the optimization of specimens design and the manufacturing process; E.G., O.B., and J.N.L. organized, carried out, and elaborated the results of high-temperature tensile tests and their post-test microstructural analyses; L.R. performed the microhardness and microstructural observations; G.T. performed thermodynamic calculations; E.G. and G.T. discussed mechanical-microstructural correlations; E.G. wrote the draft and all the authors revised and improved it.

Acknowledgments: The authors would like to thank Raffineria Metalli Capra for the supplying of alloys and SAEN for the high-pressure diecasting of specimens. The process development to produce the investigated material was carried out within the NADIA Project, supported by the European Union (FP6-2006, grant agreement No. 026563-2).

Conflicts of Interest: The authors declare no conflict of interest.

\section{References}

1. Kaufman, J.G.; Rooy, E.L. Aluminium Alloy Castings: Properties, Processes and Applications; ASM International: Materials Park, OH, USA, 2004; pp. 61-68, ISBN 0-87170-803-5.

2. Sjolander, E. Heat Treatment of Al-Si-Cu-Mg Casting Alloys. Ph.D. Thesis, Jönköping University, Jönköping, Sweden, 2011.

3. Lumley, R.N.; ODonnell, R.G.; Gunasegaram, D.R.; Givord, M. Heat treatment of high-pressure die castings. Metall. Mater. Trans. 2007, 38, 2564-2574. [CrossRef]

4. Hurtalova, L.; Tillova, E.; Chalupova, M. The structure analysis of secondary (recycled) AlSi9Cu3 cast alloy with and without heat treatment. Eng. Trans. 2013, 61, 197-218.

5. Jeong, C.Y. Effect of alloying elements on high temperature mechanical properties for piston alloy. Mater. Trans. 2012, 53, 234-239. [CrossRef]

6. Molina, R.; Amalberto, P.; Rosso, M. Mechanical characterization of aluminium alloys for high temperature applications Part1: Al-Si-Cu alloys. Metall. Sci. Technol. 2012, 29, 5-11.

7. Ferguson, J.B.; Lopez, H.F.; Cho, K.; Kim, C.S. Temperature effects on the tensile properties of precipitation-hardened Al-Mg-Cu-Si alloys. Metals 2016, 6, 43. [CrossRef]

8. Zamani, M.; Seifeddine, S.; Jarfors, A.E.W. High temperature tensile deformation behaviour and failure mechanisms of an Al-Si-Cu-Mg cast alloy-The microstructural scale effect. Mater. Des. 2015, 86, 361-370. [CrossRef]

9. Yousefi, M.; Dehnavi, M.; Miresmaeili1, S.M. Microstructure and impression creep characteristics of Al-9Si- $x \mathrm{Cu}$ aluminium alloys. Metall. Mater. Eng. 2015, 21, 115-125. 
10. EN 1706 Standard, Aluminium and Aluminium Alloys. Castings. Chemical Composition and Mechanical Properties; CEN-Comité Européen de Normalisation: Brussel, Belgium, 2007.

11. ASTM B85/B85M-14 Standard Specification for Aluminum-Alloy Die Castings; ASTM International: West Conshohocken, PA, USA, 2014.

12. Timelli, G.; Ferraro, S.; Groselle, F.; Bonollo, F.; Voltazza, F.; Capra, L. Caratterizzazione meccanica e microstrutturale di leghe di alluminio pressocolate. Metall. Ital. 2011, 1, 5-16.

13. Timelli, G.; Bonollo, F. Quality mapping of aluminum alloy die castings. Metall. Sci. Technol. 2008, 26, 2-8.

14. Ferrero, S.; Timelli, G. Influence of sludge particles on the tensile properties of die cast secondary aluminium alloys. Metall. Mater. Trans. B 2015, 46, 1022-1034. [CrossRef]

15. Ozhoga-Maslovskaja, O.; Gariboldi, E.; Lemke, J.N. Conditions for blister formation during thermal cycles of Al-Si-Cu-Fe alloys for high pressure diecasting. Mater. Des. 2016, 92, 151-159. [CrossRef]

16. ISO 6892-2:2011. Metallic Materials-Tensile Testing-Part 2: Method of Test at Elevated Temperature; ISO: Geneva, Switzerland, 2011.

17. CEN T/R 16748:2014 Aluminium and Aluminium Alloys. Mechanical Potential of Al-Si Alloys for High Pressure, Low Pressure and Gravity Die Casting; CEN-Comité Européen de Normalisation: Brussel, Belgium, 2014.

18. Ramberg, W.; Osgood, W.R. Description of Stress-Strain Currves by Three Parameters; Technical Note No. 902; National Advisory Committee for Aeronautics: Washington, DC, USA, 1943.

19. Wiesner, D.J.; Watkins, T.R.; Ely, T.M.; Spooner, S.; Hubbard, C.R.; Williams, J.C. Residual stress measurements of cast aluminum engine blocks using diffraction. JCPDS-Int. Centre Diffr. Data Adv. X-ray Anal. 2005, 48, 136-142.

20. Rossi, J.L.; Pilkington, R.; Trumper, R.L. Graphical Manipulation of EDS Data Obtained by SEM. In Proceedings of the 13 International Conference UMST X Ray Optics and Microanalysis 1992, Manchester, UK, 31 August-4 September 1992; pp. 275-278.

21. Hatch, J.E. Aluminium: Properties and Physical Metallurgy, 10th ed.; ASM International: Materials Park, OH, USA, 2005; p. 238, ISBN 978-0871701763.

22. Rana, R.S.; Purohit, R.; Das, S. Reviews on the influences of alloying elements on the microstructure and mechanical properties of aluminum alloys and aluminum alloy composites. Int. J. Sci. Res. Publ. 2012, 2, 1-7.

23. Belov, N.A.; Aksenov, A.A.; Eskin, D.G. Iron in Aluminium Alloys-Impurity and Alloying Element; Taylor and Francis: London, UK, 2002; pp. 78-80, ISBN 9780415273527.

24. Kaufmann, H.; Fragner, W.; Uggowitzer, P.J. Influence of variations in alloy composition on castability and process stability. Part 1: Gravity and pressure casting. Int. J. Cast Met. Res. 2005, 18, 273-278. [CrossRef]

25. Ferraro, S.; Fabrizi, A.; Timelli, G. Evolution of sludge particles in secondary die-cast aluminum alloys as function of Fe, Mn and Cr contents. Mater. Chem. Phys. 2015, 153, 168-179. [CrossRef]

26. Dorè, X.; Combeau, X.; Rappaz, M. Modelling of microsegregation in ternary alloys: Application to the solidification of Al-Mg-Si. Acta Mater. 2000, 48, 3951-3962. [CrossRef]

27. Kaufmann, H.; Uggowitzer, P.J. Metallurgy and Processing of High Integrity Light Metal Pressure Castings; Schiele \& Schon: Berlin, Germany, 2007; pp. 7-12, 187-191, ISBN 9783794907540.

28. Zoqui, E.J. Alloys for semisolid processing. In Comprehensive Materials Processing, Volume 5-Casting, Semi-Solid Forming and Hot Metal Forming; Hashmi, S., Ed.; Elsevier: New York, NY, USA, 2014; pp. 163-188, ISBN 9780080965338.

29. Shabestari, S.G. The effect of iron and manganese on the formation of intermetallic compounds in aluminum-silicon alloys. Mater. Sci. Eng. A 2004, 383, 289-298. [CrossRef]

30. Cao, X. Effect of iron and manganese contents on convection-free precipitation and sedimentation of primary $\alpha-\mathrm{Al}(\mathrm{FeMn}) \mathrm{Si}$ phase in liquid Al-11.5Si-0.4Mg alloy. J. Mater. Sci. 2004, 39, 2303-2314. [CrossRef]

31. Ferdian, M.D. Effect de la Vitesse de Refroidissment sur la Taille des Grains, la Modification Eutectique et la Precipitation D'intermetalliques Riches en fer dans des Alliages Al-Si Hypotectiques. Ph.D. Thesis, Universitè de Tolouse, Toulouse, France, 2014.

32. Karl, M.V. A crystallographic identification of intermetallic phases in Al-Si alloys. Mater. Lett. 2005, 59, 2271-2276. [CrossRef]

33. Taylor, J.A. Iron-containing intermetallic phases in Al-Si based casting alloys. Procedia Mater. Sci. 2012, 1, 19-33. [CrossRef]

34. Ji, S.; Yang, W.; Gao, F.; Watson, D.; Fan, Z. Effect of iron on the microstructure and mechanical property of Al-Mg-Si-Mn and Al-Mg-Si diecast alloys. Mater. Sci. Eng. A 2013, 564, 30-139. [CrossRef] 
35. Timelli, G.; Fabrizi, A. The effects of microstructure heterogeneities and casting defects on the mechanical properties of high-pressure die-cast AlSi9Cu3(Fe) Alloys. Metall. Mater. Trans. A 2014, 45, 5486-5498. [CrossRef]

36. Mohamed, A.M.A.; Samuel, A.M.; Samuel, F.H.; Doty, H.W. Influence of additives on the microstructure and tensile properties of near-eutectic Al-10.8\% Si cast alloy. Mater. Des. 2009, 30, 3943-3957. [CrossRef]

37. Czerwinski, F.; Shaha, S.K.; Kasprzak, W.; Friedman, J.; Chen, D.L. Aging characteristics of the Al-Si-Cu-Mg cast alloy modified with transition metals Zr, V and Ti. IOP Conf. Ser. Mater. Sci. Eng. 2016, 117, 012031. [CrossRef]

38. Bassani, P.; Gariboldi, E.; Ripamonti, D. Thermal analysis of Al-Cu-Mg-Si alloy with Ag/Zr additions. J. Therm. Anal. Calorim. 2008, 91, 29-35. [CrossRef]

39. Samuel, A.M.; Gauthier, J.; Samuel, F.H. Microstructural Aspects of the Dissolution and Melting of $\mathrm{Al}_{2} \mathrm{Cu}$ Phase in Al-Si Alloys during Solution Heat Treatment. Metall. Mater. Trans. A 1996, 27, 1785-1798. [CrossRef]

(C) 2018 by the authors. Licensee MDPI, Basel, Switzerland. This article is an open access article distributed under the terms and conditions of the Creative Commons Attribution (CC BY) license (http:/ / creativecommons.org/licenses/by/4.0/). 